\title{
High-level expression and characterization of a chimeric lipase from Rhizopus oryzae for biodiesel production
}

\author{
Xiao-Wei Yu ${ }^{1}$, Chong Sha ${ }^{1}$, Yong-Liang Guo ${ }^{1}$, Rong Xiao ${ }^{2}$ and Yan $\mathrm{Xu}^{{ }^{*}}$
}

\begin{abstract}
Background: Production of biodiesel from non-edible oils is receiving increasing attention. Tung oil, called "China wood oil" is one kind of promising non-edible biodiesel oil in China. To our knowledge, tung oil has not been used to produce biodiesel by enzymatic method. The enzymatic production of biodiesel has been investigated extensively by using Rhizopus oryzae lipase as catalyst. However, the high cost of R. oryzae lipase remains a barrier for its industrial applications. Through different heterologous expression strategies and fermentation techniques, the highest expression level of the lipase from $R$. oryzae reached $1334 \mathrm{U} / \mathrm{mL}$ in Pichia pastoris, which is still not optimistic for industry applications.

Results: The prosequence of lipases from Rhizopus sp. is very important for the folding and secretion of an active lipase. A chimeric lipase from $R$. oryzae was constructed by replacing the prosequence with that from the $R$. chinensis lipase and expressed in P. pastoris. The maximum activity of the chimera reached $4050 \mathrm{U} / \mathrm{mL}$, which was 11 fold higher than that of the parent. The properties of the chimera were studied. The immobilized chimera was used successfully for biodiesel production from tung oil, which achieved higher FAME yield compared with the free chimeric lipase, non-chimeric lipase and mature lipase. By response surface methodology, three variables, water content, methanol to tung oil molar ratio and enzyme dosage were proved to be crucial parameters for biosynthesis of FAME and the FAME yield reached $91.9 \pm 2.5 \%$ at the optimized conditions by adding $5.66 \mathrm{wt} . \%$ of the initial water based on oil weight, 3.88 of methanol to tung oil molar ratio and 13.24 wt.\% of enzyme concentration based on oil weight at $40^{\circ} \mathrm{C}$.

Conclusions: This is the first report on improving the expression level of the lipase from $R$. oryzae by replacing prosequences. The immobilized chimera was used successfully for biodiesel production from tung oil. Using tung oil as non-edible raw material and a chimeric lipase from $R$. oryzae as an economic catalyst make this study a promising one for biodiesel applications.
\end{abstract}

Keywords: Biodiesel, Lipase, Chimera, Prosequence, Rhizopus oryzae, Pichia pastoris, Tung oil

\section{Background}

During the past decades biodiesel (monoalkyl esters of long-chain fatty acids) is receiving increasing attention as an alternative diesel fuel because of its favorable properties, environmental benefits and the fact that is derived from the renewable biological resources [1,2]. At present, biodiesel is mainly produced from edible oils

\footnotetext{
* Correspondence: biosean@yahoo.com.cn

'State Key Laboratory of Food Science and Technology, the Key Laboratory of Industrial Biotechnology, Ministry of Education, School of Biotechnology, Jiangnan University, 1800 Lihu Avenue, Wuxi 214122, Jiangsu, China Full list of author information is available at the end of the article
}

(more than 95\%), such as soybean oil, rapeseed oil and palm oil, which leads to global imbalance to the food supply and demand market. One alternative way is to produce biodiesel from low cost non-edible oils. Most of the non-edible plants can be grown in wasteland and infertile land, which allows the use of wasteland to produce oil crops for biodiesel production without the need to compete with food crops for the limited arable land $[3,4]$. Thus, focus should be shifted to the sustainable non-edible resources which will be crucial determinants in the popularization of biodiesel. 
Tung oil, called "China wood oil" is one kind of promising non-edible biodiesel oil in China. Tung trees are spread widely in China. The oil content of the seeds and whole nuts is approximately 21 and $41 \mathrm{wt} . \%$, respectively. The productivity of tung oil is from 300 to $450 \mathrm{~kg} / \mathrm{ha}$, obtained by pressing the seeds of the tung tree. Unlike vegetable oils that contain high amounts of saturated fatty acids, tung oil is composed of more than $60 \%$ unsaturated fatty acid, mainly $9 \mathrm{Z}, 11 \mathrm{E}, 13 \mathrm{E}$ - $\alpha$-elaeostearic acid [5,6]. Generally, saturated fatty acid methyl esters have good oxidation stability and poor low temperature properties. On the contrary, unsaturated fatty acid methyl esters have good low temperature properties and poor oxidation stability [6]. The shortcomings of tung oil methyl esters could be solved by blending with palm, coconut and canola oil biodiesels [5,7].

Biodiesel could be produced by chemical or enzymatic methods according to the catalysts employed in the process. Contrary to chemical catalysts, enzymatic method does not form soaps and can esterify both FFA and TAG in one step without the need of a subsequent washing step $[2,8]$. This is especially the case when using feeds high in FFA such as tung oil. To our knowledge, tung oil has not been used to produce biodiesel by enzymatic method, except for several reports by chemical method $[6,7,9,10]$.

Nowadays biodiesel production by lipase-catalyzed transesterification becomes an interesting prospect in an industrial scale. The enzymatic production of biodiesel has been investigated extensively by using Rhizopus oryzae lipase (ROL) [11,12]. The free $R$. oryzae lipase F-APl5 (Amano) catalyzed the methanolysis of soybean oil which reached 80 wt.\% yield of fatty acid methyl esters (FAME) by stepwise additions of methanol to the reaction mixture in the presence of $4 \sim 30 \mathrm{wt} . \%$ water [13]. The crude recombinant $R$. oryzae lipase LY6 by Pichia pastoris immobilized on anion exchange resin Amberlite IRA-93 was used to biosynthesis biodiesel from soybean oil and the highest biodiesel yield was achieved at $90.5 \%$ [14].

However, the high cost of the catalyst ROL remains a barrier for its industrial applications. In order to bring the cost down, one of the options is to enhance the expression level of $R$. oryzae lipases. The production of active $R$. oryzae lipases has been performed in Escherichia coli [15], in Saccharomyces cerevisiae [16,17] and in $P$. pastoris [18-20]. Lorenzo et al. [15] successfully expressed the $R$. oryzae prolipase (proROL) in a soluble form in $E$. coli with an activity of $166 \mathrm{U} / \mathrm{mL}$ (protein concentration $1.5 \mathrm{mg} / \mathrm{mL}$ ). Takahashi et al. [17] reported that the activity of proROL by $S$. cerevisiae reached $2.88 \mathrm{U} / \mathrm{mL}$ (protein concentration $28.0 \mathrm{mg} / \mathrm{L}$, $O D_{600}$ about 90) after $120 \mathrm{~h}$ of cultivation in YPD medium. The activity of $R$. arrhizus prolipase expressed in $P$. pastoris was obtained at $140 \mathrm{U} / \mathrm{mL}(4375 \mathrm{U} / \mathrm{g}$ dry cell weight and $91 \mathrm{mg}$ enzyme/L broth) after $92 \mathrm{~h}$ of cultivation in complex medium [21]. The activity of the mature lipase from $R$. oryzae (mROL) expressed in $P$. pastoris reached $500 \mathrm{U} / \mathrm{mL}(60 \mathrm{~g}$ wet cell weight/L and $60 \mathrm{mg}$ enzyme/L) [20]. And the activity of this lipase was further improved to $1334 \mathrm{U} / \mathrm{mL}$ (about $48 \mathrm{~g}$ dry cell weight/L) by a methanol feeding strategy [18], which was the highest expression level ever reported. However, through different heterologous expression strategies and fermentation techniques, the expression level of $R$. oryzae lipases is still not optimistic for industry applications.

The prosequenes in some proteolytic enzyme precursors inhibit the activity of the mature portions, while some of the prosequences have the function to help folding of the mature portions, such as subtilisin E of Bacillus subtilis [22], carboxypeptidase Y of S. cerevisiae [23], and lipases from Rhizopus sp. [24,25]. The lipase secreted from $R$. oryzae, similar to the lipases from $R$. chinensis, Rhizomucor miehei and Fusarium heterosporum, is synthesized as a precursor form with a presequence (23 amino acid residues) and a prosequence (97 amino acid residues) at the $\mathrm{N}$-terminal side of the mature portion (268 amino acid residues) [24,25]. In E. coli, the activity of the prolipase could reach $100 \mathrm{U} / \mathrm{mL}$, while the mature portion of ROL was expressed as an insoluble form without activity. The mutation studies demonstrated that the prosequence of ROL seems to facilitate the folding by providing an intramolecular thiol-disulfide reagent, and proROL is also significantly more stable against thermal inactivation than mROL $[25,26]$. For the expression of $R$. arrhizus lipases in $P$. pastoris, the pro-form lipase (r28RAL) and the mature portion of the lipase in the supernatant reached $91 \mathrm{mg} / \mathrm{L}$ and $80 \mathrm{mg} / \mathrm{L}$, respectively [21]. Takahashi et al. [24] explored the role of the prosequence of ROL expressed in S. cerevisiae and indicated that the prosequence might support the correct folding of its mature portion and its subsequent secretion from the yeast cells.

In this study, we constructed a chimeric lipase from $R$. oryzae by replacing the prosequence with that from $R$. chinensis lipase and successfully expressed in $P$. pastoris at high-level. The chimera was characterized and its performance for biodiesel production from nonedible tung oil was investigated by response surface methodology.

\section{Results and discussion}

\section{Design of the chimeric lipase}

Rhizopus sp. are mainly divided into three groups, including $R$. microsporus, $R$. oryzae, $R$. stolonifer [27]. In our previous study, a lipase gene (GenBank accession No. EF405962) cloned from $R$. chinensis CCTCC 
M201021 (belongs to $R$. microsporus) was expressed at high-level $(2130 \mathrm{U} / \mathrm{mL})$ in $P$. pastoris which was about 580 times higher than that of the wild-type $R$. chinensis lipase $[28,29]$. We noticed a big gap between the expression level of the $R$. chinensis lipase (RCL) and the $R$. oryzae lipase. Rhizopus sp. lipases are synthesized as prepro-proteins. In vivo expression and in vitro refolding experiments of $R$. oryzae lipase showed that the prosequence was very important for the folding and secretion of an active lipase [24-26]. Through analysis, the deviation of the prosequences between RCL and ROL let us come up with an idea to construct a chimeric lipase from $R$. oryzae by replacing the prosequence with that from $R$. chinensis lipase in order to improve the expression level of the lipase from $R$. oryzae.

The cloned DNA sequence of the prepro-lipase gene from $R$. oryzae XY1 was 1176 bp shared $99.75 \%$ with the $R$. oryzae lipase gene sequence (GenBank accession No. AF229435) and 100\% homology with the amino acid sequence. Amino acid sequence alignment shows that $R$. oryzae lipase was most closely related to RCL with $75.6 \%$ homology (Figure $1 \mathrm{~A}$ ). They both contain the conserved catalytic triad S-H-D indicated by star (Figure 1A). However, the prosequence from the $R$. oryzae lipase only shared $47.4 \%$ identity with that from the $R$. chinensis lipase. Compared to the $R$. oryzae lipase, the much higher expression level of the $R$. chinensis lipase in $P$. pastoris was probably contributed by the different amino acid composition of the prosequence. The chimeric $R$. oryzae lipase was constructed by replacing the prosequence with that from the $R$. chinensis lipase, named as proAROL (Figure 1B), in an aim to improve the expression level of the lipase from $R$. oryzae.

\section{Expression and properties of the chimeric lipase}

As shown in Figure 2, after replacing the prosequence, the activity of the chimeric lipase proAROL reached the maximum of $4050 \mathrm{U} / \mathrm{mL}$ by $p \mathrm{NPP}$ assay after induction of $76 \mathrm{~h}$, which was 11 fold higher than that of the parent. It was probably that the increased lipase activity of the chimera was induced by an increased secretion or an increased catalytic rate. To explore the reason, we investigated the differences of the total protein concentrations in the supernatant, cell concentrations and the kinetic parameters between the chimeric lipase and the non-chimeric lipase. The cell concentrations (DCW, dry cell weight) were very similar, while the total protein concentration of the supernatant expressed by GS115/pPIC9K-proAROL increased significantly by 9.6 times, which was also evident in SDS-PAGE (Figure 3). The specific lipase production ( $p$ NPP assay) reached $33750 \mathrm{U} / \mathrm{g}$ dry cell weight for the chimeric

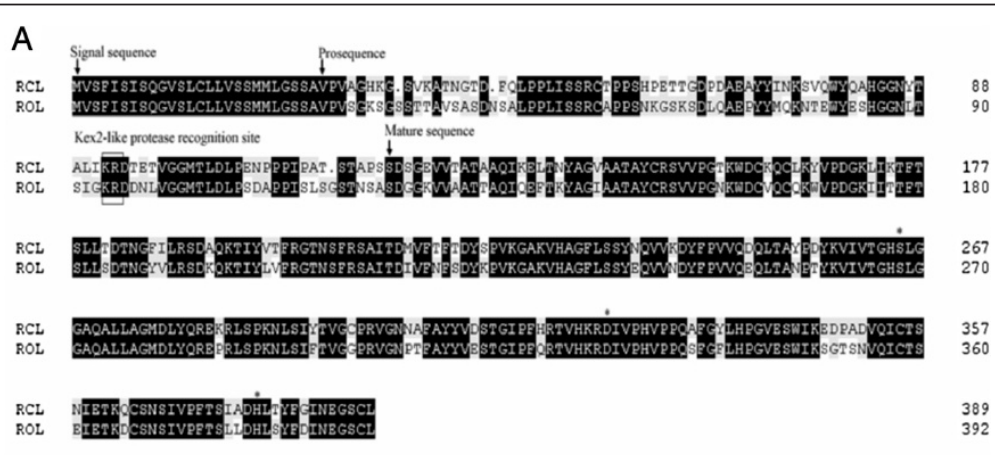

B prosequence mature sequence

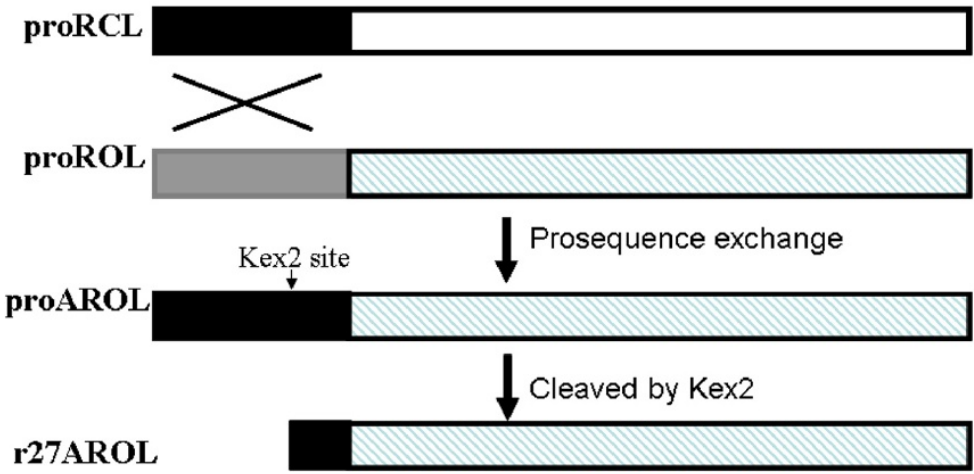

Figure 1 (A) Alignment of amino acid sequences from $R$. oryzae lipase and $R$. chinensis lipase; (B) Scheme of the chimeric lipases proAROL and r27AROL. 


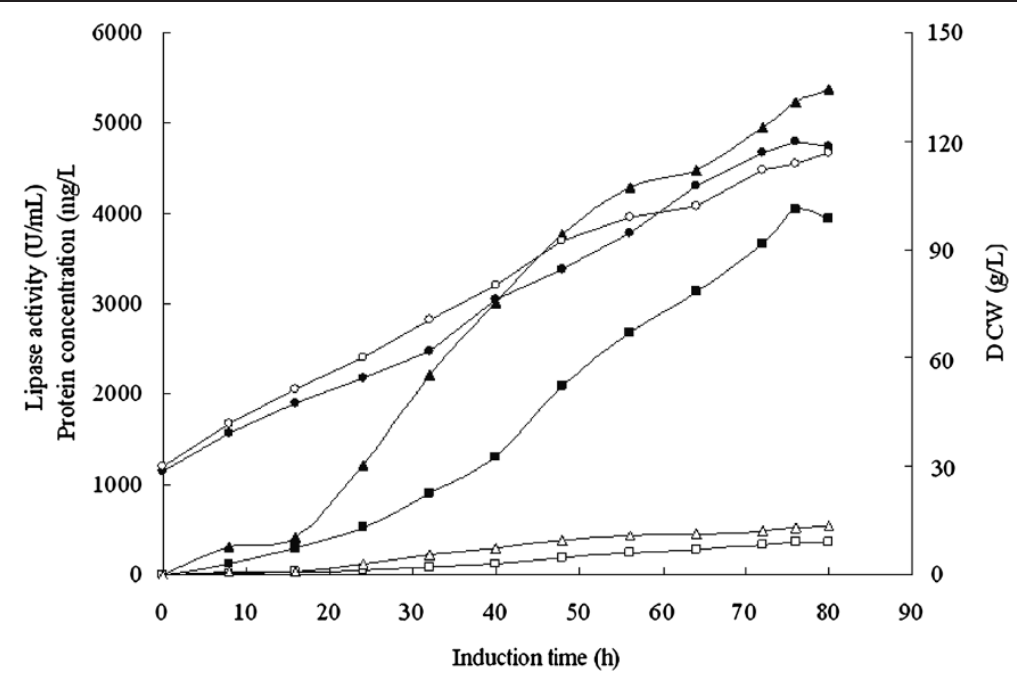

Figure 2 Lipase activity, protein concentration, cell concentration profiles of GS115/pPIC9K-proROL and GS115/pPIC9K-proAROL. Lipase activity by pNPP assay: $(\mathbf{\square})$ chimera, $(\square)$ parent; Protein concentration: $(\mathbf{\Lambda})$ chimera, $(\Delta)$ parent; Cell concentration: $(\bullet)$ chimera, $(\mathrm{O})$ parent.

lipase and $3068 \mathrm{U} / \mathrm{g}$ dry cell weight for the nonchimeric lipase, and the specific lipase activity reached $779 \mathrm{U} / \mathrm{mg}$ protein by $p \mathrm{NPP}$ assay $(2493 \mathrm{U} / \mathrm{mg}$ protein by $\mathrm{pH}$-stat assay) for the chimeric lipase and $681 \mathrm{U} / \mathrm{mg}$ protein by $p \mathrm{NPP}$ assay $(2078 \mathrm{U} / \mathrm{mg}$ protein by $\mathrm{pH}-$ stat assay) for the non-chimeric lipase. On SDS-PAGE the target band of the chimera was much thicker than that of the parent and both recombinant lipases migrated as a single band with a molecular mass of about $37 \mathrm{kDa}$, which was lower than the calculated

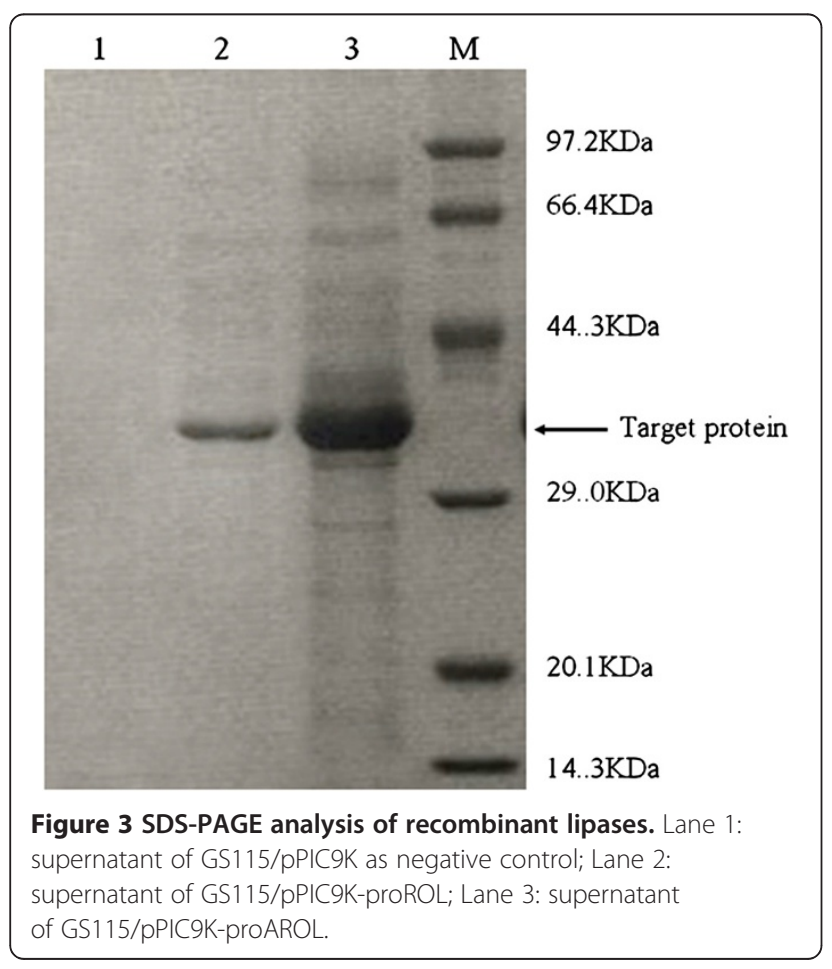

molecular weights of proROL and proAROL $(39 \mathrm{kDa})$. We further purified the chimera and non-chimera for analysis of the $\mathrm{N}$-terminal amino acid sequences and enzymatic properties. The $\mathrm{N}$-terminal sequence of the secreted chimeric lipase, named as r27AROL, was D-T-ET-V-G-G, corresponding to 27 amino acids of C-terminal part of the prosequence of proAROL, and the $\mathrm{N}$-terminal sequence of the secreted wild type, named as r28ROL, was D-D-N-L-V-G-G, which retained 28 amino acids of Cterminal part of the prosequence of proROL. The results suggested that the secreted lipases was cleaved by Kex2like protease in P. pastoris at the recognition site LysArg of the prosequences, which was also observed in other reports $[28,30]$. The kinetic parameters were determined using $p$-nitrophenyl palmitate $(p N P P)$ as substrate. The interfacial kinetic parameter $K_{\mathrm{m}}^{\prime}$ value for the chimera was not changed compared to the parent and the $k_{\text {cat }}^{\prime \prime}$ value was 1.32 times higher than that of the parent. The results suggested that the increased secretion of the chimeric lipase was the main factor for the much higher lipase activity of the chimera in the supernatant but the improved catalytic rate of the chimera only contributed a little. The highest expression level previously reported on a mature $R$. oryzae lipase expressed in P. pastoris was $1334 \mathrm{U} / \mathrm{mL}$ (pH-stat assay using olive oil emulsion as substrate) with the specific lipase production of $27791 \mathrm{U} / g$ dry cell weight [18], which was lower than the expression level of the chimera in this study. However, these values are not fully comparable since different activity assays with different substrates and conditions have been used. In order to reach a more comparable level, the activity of the same chimeric lipase sample was measured in parallel by both $p \mathrm{NPP}$ assay and $\mathrm{pH}$-stat assay. The results indicated that the lipolytic activity values reported 
in the present work were an underestimation since the activity by $\mathrm{pH}$-stat assay $(12960 \mathrm{U} / \mathrm{mL})$ was about 3 times higher than that by $p$ NPP assay $(4050 \mathrm{U} / \mathrm{mL})$.

Both lipases exhibited maximum activity at $\mathrm{pH} 8.5$ and could keep more than $80 \pm 2 \%$ of the maximum activity after incubating at pH 7.0 9.0 for $24 \mathrm{~h}$. However, the lipase activity decreased dramatically when temperature was over $50^{\circ} \mathrm{C}$ or $\mathrm{pH}$ was over 10.0 . The optimum temperature for both lipases was $40^{\circ} \mathrm{C}$. r27AROL could keep $85 \pm 3 \%$ of the maximum activity after incubating for $1 \mathrm{~h}$ at $40^{\circ} \mathrm{C}$, and $\mathrm{r} 28 \mathrm{ROL}$ retained $70 \pm 2 \%$ residual activity at the same condition. The prosequence from Rhizopus sp. not only supports folding of the lipases but also has the function to improve the thermostability of the prolipase compared with the mature lipase, such as the $R$. oryzae lipases expressed in E. coli [26], the $R$. chinensis lipases [28] and the $R$. arrhizus lipases expressed in $P$. pastoris [21]. In agreement with these reports, the thermostability of the mature $R$. oryzae lipase by $P$. pastoris in this study was also much lower than those of r28ROL and r27AROL, which retained $55 \pm 3 \%$ residual activity with the same heat treatment.

The mechanism of the prosequence of the lipases from Rhizopus sp. seems to be more complicated. In the case of proROL produced in E. coli, Beer et al. [26] presumed that cysteine-30 in the prosequence might play a key role in facilitating the folding of the enzyme and work as an intramolecular disulfide reagent, analogously to the role of the cysteine residue in the prosequence of pro-bovine pancreatic trypsin inhibitor [31]. While on the contrary Takahashi et al. [24] found that the mutation from cysteine-30 to serine in the prosequence of proROL expressed in $S$. cerevisiae did not affect the activity in either extra- or intracellular fractions. They proposed a model on the behavior of ROL in the ER lumen of $S$. cerevisiae. ROL with the wild-type prosequence is folded correctly by the function of the prosequence in the ER lumen and secreted extracellularly. Certain deletions in the prosequence block correct folding of the mature portion, so that ROLs with the mutated prosequences are retained in the ER lumen. Moreover, N-linked glycosylation might also influence the secretion and thermostability of enzymes [32,33]. The lipase from $R$. oryzae has three potential sites of $\mathrm{N}$-glycosylation, one being in the prosequence and others in the mature portion [24]. The mutation of the glycosylation site in the prosequence of this enzyme did not affect either the secretion of active lipase [24] or the thermostability of proROL [30]. However, the prosequence from $R$. chinensis lipase contained three potential $\mathrm{N}$-glycosylation sites, which might be the contributor for the high secretion and thermostability for the chimera r27AROL. Further analysis is necessary to make clear the differences between the prosequences from $R$. oryzae lipase and $R$. chinensis lipase. And to elucidate the structural relationship between the prosequence and mature portion, crystallographic analysis is ongoing in our further research.

\section{Comparison of the production of FAME from tung oil by the lipases}

Immobilization is the key to the operational performance of an enzyme in industrial processes, particularly for reuse in nonaqueous media [34]. Resin has been often used for immobilization of enzymes for use in nonaqueous media, which involves dispersal of enzyme over a large surface. The chimeric lipase r27AROL was immobilized on anion exchange resin Amberlite IRA-93 and the performance of FAME production by the lipases was compared among the immobilized r27AROL and the free enzymes. Figure 4 shows the FAME formation at $24 \mathrm{~h}, 48 \mathrm{~h}$ and $72 \mathrm{~h}$ in the reaction media at $40^{\circ} \mathrm{C}$. All four enzymes showed a higher conversion at $48 \mathrm{~h}$ than that at $24 \mathrm{~h}$ and to extend the reaction time to $72 \mathrm{~h}$ did not further increase the FAME yields. Under the same indicated reaction condition the FAME yield by immobilized r27AROL was higher than all three free lipases, which reached $89.5 \pm 2.2 \%$ at $48 \mathrm{~h}$. The immobilized enzymes are generally known to give better transformation rates in nonaqueous media due to the larger surface area of the immobilized biocatalyst. On the contrary, free enzyme usually suffers mass transfer problem in low water media [34]. The free chimeric r27AROL exhibited better performance than the free non-chimeric r28ROL and free mature mROL, probably due to the different thermostability. r27AROL was the most thermostable lipase among them, while $\mathrm{mROL}$ without the prosequence showed the lowest thermostability.

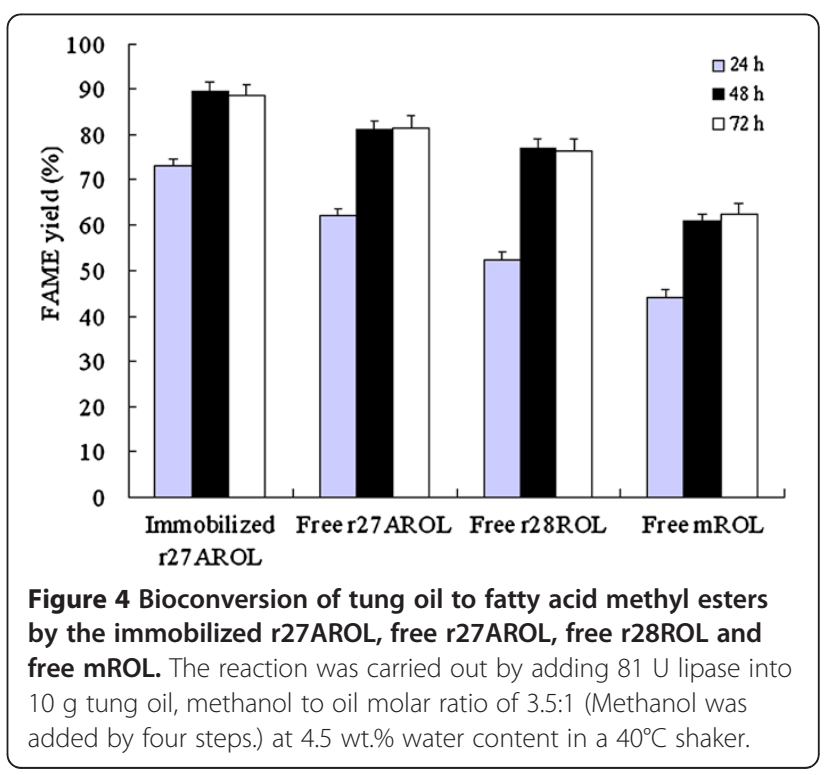




\section{Optimization of the production of FAME by response surface methodology}

Response surface methodology (RSM), one of the global optimization methods, helps in evaluating the effective factors and in building models to study interaction, and to select optimum conditions of variables for a desired response. In this study, RSM was adopted to optimize the process of methanolysis of tung oil to FAME by the immobilized chimeric lipase from $R$. oryzae. Based on the results obtained from single factor experiments and other most commonly used factors in the transesterification reactions catalyzed by $R$. oryzae lipases $[13,35,36]$, the major factors affecting the transesterfication were water content, ratio of methanol to oil, and enzyme dosage. A five-level-three-factor central composite rotatable design (CCRD) was adopted to evaluate the effects of the above three factors on the FAME yield. The corresponding CCRD and experimental data were shown in Table 1 and Table 2, respectively. The data was fitted to quadratic polynomial model using the software Design-Expert 8.0.7.1, and the polynomial model for the yield of FAME was given below (in terms of actual factors):

$$
\begin{aligned}
\text { Fame yield }(\%)= & -112.744+23.289 A+24.826 B \\
& +13.794 C-0.700 \mathrm{AB}-0.376 \mathrm{AC} \\
& -0.167 \mathrm{BC}-1.378 A^{2}-2.405^{2} \\
& -0.416 C^{2}
\end{aligned}
$$

Where FAME yield (\%) is the response value, A is the initial water added based on oil weight (wt. \%), B is methanol to tung oil molar ratio $(\mathrm{mol} / \mathrm{mol})$, and $\mathrm{C}$ is enzyme concentration based on oil weight (wt.\%).

The results obtained were than analyzed by ANOVA to assess the goodness of fit. The ANOVA of the model and respective model terms are tabulated in Table 3. The Model F-value of 31.80 implies the model is significant. There is only a $0.01 \%$ chance that a "Model F-Value" this large could occur due to noise, indicating that the quadratic model is reliable in predicting the FAME yield. Values of "Prob > F" less than 0.0500 indicate model terms are significant. In this study, it was observed that all the linear and quadratic terms of water content (A), molar ratio of methanol to oil (B), and enzyme dosage (C) had a significant effect on the FAME yield. Besides that, the effect of interaction between water content and molar ratio of methanol to oil $(\mathrm{AB})$ also affected the FAME yield significantly. To test the fit of the model, the coefficient of determination $\left(R^{2}\right)$ were evaluated, which was 0.9662 indicating that the model does not explain only $3.38 \%$ of total variations. The adjusted determination coefficient (Adj $R^{2}=0.9359$ ) was also high to advocate for a high significance of the model.

The entire relationships between reaction factors and response could be better understood by examining contour plots and response surface curves generated from the predicted model Eq. (1). As shown in Figure 5, all three contour plots were convex nature indicating that there were well-defined optimum operating conditions for the transesterification of FAME.

Usually, in nonaqueous media an optimum amount of water was needed for biocatalysis. Lipases possess the unique feature of acting at the aqueous and nonaqueous interface. Activation of lipase involves the opening of the lid on the oil-water interface, hence allowing substrates access to the active site [37]. Therefore, the transesterification yields and the activity of the lipase in nonaqueous media depend on the size of interfacial area which can be increased by the addition of certain amounts of water. However, since lipases usually catalyze hydrolysis in aqueous media, excess water may also stimulate the competing hydrolysis reaction. The optimum water content is a compromise between minimizing hydrolysis and maximizing enzyme activity for the transesterification reaction [38]. Figure 5A shows contour plots regarding the effects of water content, methanol to oil molar ratio and their interactions on FAME yield at a constant enzyme dosage of $12.5 \mathrm{wt} . \%$. The elliptical curves of the contour plots indicated that the interaction between water and methanol was strong [39], where both water content and methanol content are critical parameters for lipase activity, and water affects the distribution of water molecules present in the reaction system. When the water content was in the range from $4.40 \mathrm{wt} . \%$ to 7.09 wt.\% with the methanol to oil molar ratio between 2.87 and 4.92, the FAME yield would exceed $90 \%$. With the water content as low as 0.3 wt.\%, the lipase activity was very low and the FAME yield could

\begin{tabular}{|c|c|c|c|c|c|c|}
\hline \multirow[t]{2}{*}{ Variables } & \multirow[t]{2}{*}{ Symbols } & \multicolumn{5}{|c|}{ Levels } \\
\hline & & $-1.68(-a)$ & -1 & 0 & +1 & $+1.68(+a)$ \\
\hline Initial water added based on oil weight (wt.\%) & A & 0.30 & 2.00 & 4.50 & 7.00 & 8.70 \\
\hline Methanol to tung oil molar ratio $(\mathrm{mol} / \mathrm{mol})$ & B & 0.98 & 2.00 & 3.50 & 5.00 & 6.02 \\
\hline Enzyme concentration based on oil weight (wt.\%) & C & 8.3 & 10.00 & 12.50 & 15.00 & 16.70 \\
\hline
\end{tabular}
only reach about $40 \%$. With the increased addition of water there was a considerable increase in the ester

Table 1 Independent variables: coded and real value in center composite rotatable design 
Table 2 Central composite rotatable design arrangement and responses

\begin{tabular}{|c|c|c|c|c|c|}
\hline \multirow[b]{2}{*}{ Design point } & \multicolumn{3}{|c|}{ Variable levels } & \multicolumn{2}{|c|}{ Yield (\%) } \\
\hline & A: water content (wt. \%) & B: Methanol to oil molar ratio & C: Enzyme concentration (wt. \%) & Experimental & Predicted \\
\hline 1 & 2.00 & 2.00 & 10.00 & 50.7 & 51.0 \\
\hline 2 & 7.00 & 2.00 & 10.00 & 81.4 & 79.7 \\
\hline 3 & 2.00 & 5.00 & 10.00 & 70.2 & 65.8 \\
\hline 4 & 7.00 & 5.00 & 10.00 & 81.2 & 83.9 \\
\hline 5 & 2.00 & 2.00 & 15.00 & 65.6 & 62.6 \\
\hline 6 & 7.00 & 2.00 & 15.00 & 77.7 & 81.8 \\
\hline 7 & 2.00 & 5.00 & 15.00 & 73.4 & 74.8 \\
\hline 8 & 7.00 & 5.00 & 15.00 & 84.2 & 83.6 \\
\hline 9 & 0.30 & 3.50 & 12.50 & 46.2 & 49.4 \\
\hline 10 & 8.70 & 3.50 & 12.50 & 83.7 & 80.9 \\
\hline 11 & 4.50 & 0.98 & 12.50 & 67.2 & 67.3 \\
\hline 12 & 4.50 & 6.02 & 12.50 & 80.8 & 81.2 \\
\hline 13 & 4.50 & 3.50 & 8.30 & 75.8 & 77.5 \\
\hline 14 & 4.50 & 3.50 & 16.70 & 88.1 & 86.9 \\
\hline 15 & 4.50 & 3.50 & 12.50 & 92.1 & 89.5 \\
\hline 16 & 4.50 & 3.50 & 12.50 & 90.9 & 89.5 \\
\hline 17 & 4.50 & 3.50 & 12.50 & 90.1 & 89.5 \\
\hline 18 & 4.50 & 3.50 & 12.50 & 90.3 & 89.5 \\
\hline 19 & 4.50 & 3.50 & 12.50 & 86.1 & 89.5 \\
\hline 20 & 4.50 & 3.50 & 12.50 & 87.7 & 89.5 \\
\hline
\end{tabular}

production showing the enhancement in the activity of the enzyme. However, at the water content beyond 7.09 wt.\%, the production of esters decreased. Tamalampudi et al. [40] also reported that the optimum water content was $5 \%(v / v)$ in Jatropha oil for producing FAME catalyzed by immobilized whole-

Table 3 ANOVA of the model and respective model terms

\begin{tabular}{llrrrl}
\hline Source & $\begin{array}{l}\text { Degree of } \\
\text { freedom }\end{array}$ & $\begin{array}{l}\text { Mean } \\
\text { square }\end{array}$ & F-Value & Prob $>$ F & Remarks \\
\hline Model & 9 & 336.95 & 31.80 & $<0.0001$ & Significant \\
A & 1 & 1193.46 & 112.63 & $<0.0001$ & Significant \\
B & 1 & 233.52 & 22.04 & 0.0008 & Significant \\
C & 1 & 106.21 & 10.02 & 0.0101 & Significant \\
AB & 1 & 55.13 & 5.20 & 0.0457 & Significant \\
AC & 1 & 44.18 & 4.17 & 0.0684 & Not significant \\
BC & 1 & 3.12 & 0.29 & 0.5990 & Not significant \\
A $^{2}$ & 1 & 1068.61 & 100.85 & $<0.0001$ & Significant \\
$B^{2}$ & 1 & 422.01 & 39.83 & $<0.0001$ & Significant \\
$C^{2}$ & 1 & 97.47 & 9.20 & 0.0126 & Significant \\
Residual & 10 & 10.60 & & & \\
Lack of fit & 5 & 16.29 & 3.32 & 0.1068 & Not significant \\
Pure error & 5 & 4.90 & & & \\
\hline
\end{tabular}

$R^{2}=0.9662, R^{2}$ (adjusted) $=0.9359$. cell $R$. oryzae lipase. The free $R$. oryzae lipase catalyzed the methanolysis of soybean oil in the presence of 4 30 wt.\% water, while the lipase was nearly inactive in the absence of water [13]. In contrast Candida antarctica lipase (Novozym 435), which shows no interfacial activation without a lid covering the entrance to the active site [41], displayed the highest activity without addition of water [40].

Methanol concentration is another crucial parameter for biosynthesis of FAME. The Excess methanol would accelerate reaction rates, while on the other hand the poor solubility of methanol in oils and good solubility in water may lead to the loss of enzyme activity. Many researchers successfully improved the biodiesel yield by adding alcohol in a stepwise manner in solvent-free system to minimize inhibition of the enzyme [42]. In this study, experiments were performed at molar ratios of methanol to oil ranging from $0.98: 1$ to $6.02: 1$ by fourstepwise addition of methanol (Figure $5 \mathrm{~A}$ and B). As was expected, an increase in the number of moles of methanol with respect to the oil resulted in an increase in the FAME yield. Ultimately, the formation of methyl esters reached a maximum level and further increases in the methanol to tung oil molar ratio resulted in a decrease in the formation of esters. This tendency was consistent with other researches which revealed that the optimum 


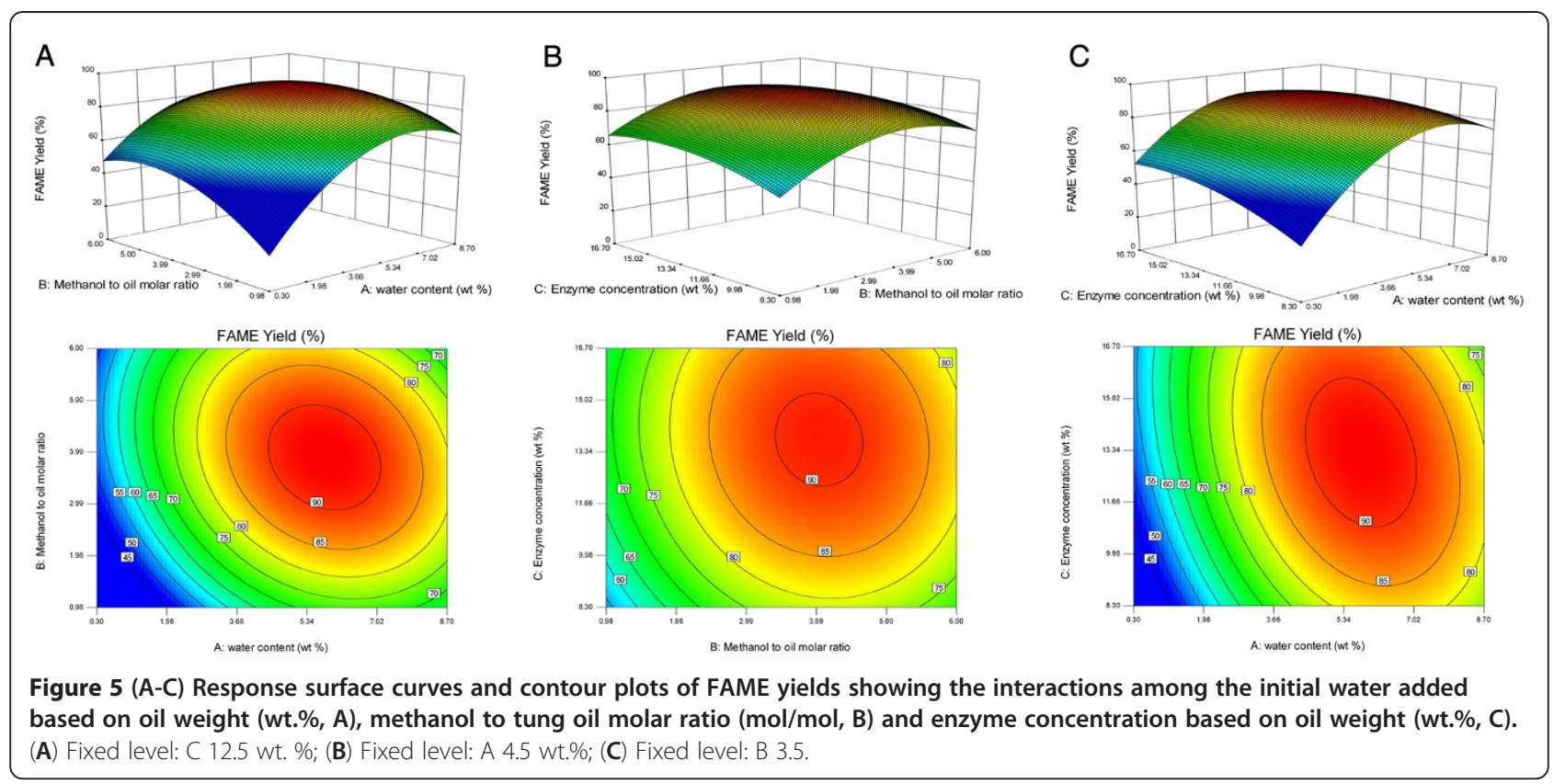

molar ratio of methanol to oil was 5:1 using immobilized $R$. oryzae lipase $[14,36]$.

Enzyme dosage may also influence the conversion of the methyl esters. The contour plots and the response surface curves in Figure $5 \mathrm{~B}$ and $\mathrm{C}$ show the predicted response surface of FAME yield as a function of enzyme dosage and water content or methanol to oil molar ratio. Enzyme loading in the range from 8.30 wt.\% to 16.70 wt.\% was examined in the transesterification of tung oil with methanol. The FAME yield above $90 \%$ was obtained in the presence of 10.83 wt.\% to 15.70 wt.\% enzyme at the water content between 4.40 wt.\% and 7.09 wt.\% with a fixed methanol to oil molar ratio of 3.5. Lower amount of immobilized enzyme would lead to lower FAME yields, while too much catalyst in the reaction system might cause mass transfer limitations. This behavior also has been observed by other researchers $[40,43]$.

\section{Optimization analysis}

The optimum conditions for the three variables were obtained using numerical optimization feature of DesignExpert 8.0.7.1. The software searches for a combination of factors that simultaneously satisfy the requirements placed on each of the response and factors. The goal was set to maximize the FAME yield in the high and low limit ranges of the three variables as stated in Table 1. The optimized condition calculated was $5.66 \mathrm{wt} . \%$ of the initial water added based on oil weight, 3.88 of methanol to tung oil molar ratio and 13.24 wt.\% of enzyme concentration based on oil weight, under which the predicted FAME yield reached $92.6 \%$. In order to verify the prediction of the model, the transesterification of tung oil with methanol using the immobilized chimeric r27AROL was carried out under the predicted optimal reaction condition. The experimental FAME yield was $91.9 \pm 2.5 \%$, a figure well within the estimated value of the model equation. The results achieved here also confirmed the validity of the predicted model.

\section{Operational stability of the immobilized r27AROL}

To further examine the potential of the immobilized r27AROL for FAME production, reusability of the lipase was investigated. After each batch reaction, the immobilized lipase was recovered by filtration and the next batch was carried out with fresh substrate. As shown in Figure $6,85.1 \pm 1.8 \%$ of its original activity was maintained after being reused for six batches, which indicated a promising application for biodiesel production.

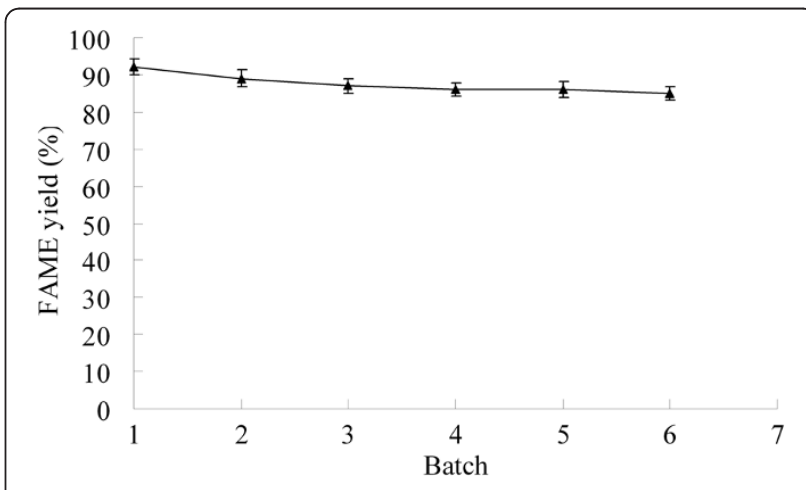

Figure 6 Operational stability of the immobilized r27AROL. 


\section{Conclusion}

Using tung oil as non-edible raw material and a chimeric lipase from $R$. oryzae as an economic catalyst make this study a promising one for biodiesel applications. In the present work, a chimeric lipase from $R$. oryzae was constructed by replacing the prosequence with that from $R$. chinensis lipase and successfully expressed in $P$. pastoris with the highest activity of $4050 \mathrm{U} / \mathrm{mL}$, which was 11 fold higher than that of the parent. This is the first report on improving the expression level of the lipase from $R$. oryzae by replacing prosequences. The immobilized chimera was used successfully for biodiesel production from tung oil, which achieved higher FAME yield compared with the free chimeric lipase, nonchimeric lipase and mature lipase. By response surface methodology, three variables, water content, methanol to tung oil molar ratio and enzyme dosage were proved to be crucial parameters for biosynthesis of FAME and the FAME yield reached $91.9 \pm 2.5 \%$ at the optimized conditions by adding $5.66 \mathrm{wt} . \%$ of the initial water based on oil weight, 3.88 of methanol to tung oil molar ratio and 13.24 wt.\% of enzyme concentration based on oil weight at $40^{\circ} \mathrm{C}$.

\section{Methods}

\section{Strains, plasmids and materials}

$R$. oryzae XY1 suitable for biodiesel production was isolated from soil and conserved in our lab, which was used for ROL gene amplification. P. pastoris GS115 and plasmid pPIC9K were purchased from the Invitrogen Company. Tung oil was purchased from Luzhou Co. Ltd. (Sichuan, China) with acid value of $2.19 \mathrm{mg} \mathrm{KOH} / \mathrm{g}$, composed of $2.8 \%$ palmitic acid (C16:0), $1.5 \%$ of stearic acid (C18:0), 5.8\% oleic acid (C18:1), 11.1\% linoleic acid (C18:2), 1.7\% linolenic acid (C18:3), 66.4\% elaeostearic acid (C18:3), 1.6\% eicosenoic acid (C20:1) and 9.2\% behenic acid (C22:0). Methyl palmitate, methyl stearate, methyl oleate, methyl linoleate, methyl linolenate, methyl elaeostearate, methyl eicosenoate, methyl behenate and methyl heptadecanoate were purchased from Sigma Co. Ltd.. 9(Z),11(E),13(E)-Octadecatrienoic acid methyl ester (methyl elaeostearate) was purchased from Cayman Chemical Co. (USA). Anion exchange resin Amberlite IRA-93 was purchased from Cangzhou Co. Ltd. (Hebei, China). All other chemicals are of analytical grade.

\section{Cloning of $R$. oryzae lipase gene, construction of the lipase expression vectors and transformation}

The open reading form of the $r o l$ gene was amplified directly from $R$. oryzae XY1 genomic DNA using a pair of primers, ROL-F1 (CCGATGGTTTCATTCA TTTCCA) and ROLR1 (GCTTACAAACAGCTTCC TTCG) according to the sequence of the lipase from $R$. oryzae (GenBank accession no. AF229435). The
PCR fragment was DNA sequenced, based on which the lipase gene without its own signal peptide (proROL) was amplified using a pair of primers, ROL-F2 (ATCCCTAGGGTTCCTGTTTCTGGTAAATC) and ROLR2 (CAGTGCGGCCGCTTACAAACAGCTTC CTTCG). The restriction sites AvrII and NotI were incorporated into the forward and reverse primer sequence, respectively. The PCR fragment was ligated into the respective sites of pPIC9K resulting in pPIC9KproROL under the control of the methanol inducible alcohol oxidase 1 promoter $\left(P_{A O X 1}\right)$ and fused in-frame with the $\alpha$-factor secretion signal peptide of $S$. cerevisiae. For construction of the chimeric lipase gene, primers RCL-F2 (ATCCCTAGGGTTCCTGTTGCTGGTCATAA AGGTTC) and RCL-PROR (GCTGGGGGCAGTGGA CGTAGCAGGAATAGG) were used to amplify the prosequence from $R$. chinensis lipase with pPIC9KproRCL [28] as template; primers ROL-MatureF (TCC TGCTACGTCCACTGCCCCCAGCTCTGATGGTGGTA AGG) and ROLR2 were used to amplify the mature lipase gene from $R$. oryzae with pPIC9K-proROL as template; then these two PCR fragments were ligated by overlap extension polymerase chain reaction (OE-PCR) to generate the chimeric lipase gene proAROL. For expression of $\mathrm{mROL}$, the mature lipase gene from $R$. oryzae was amplified using a pair of primers, ROL-mF (ATTCCTAGGTCTGATGGTGGTAAGGT) and ROLR2. The digested PCR fragments of proAROL and $m R O L$ by AvrII and NotI were ligated into the respective sites of pPIC9K resulting in pPIC9K-proAROL and pPIC9KmROL, respectively. P. pastoris GS115 was transformed with BglII-linearized plasmids by electroporation, and selection of $\mathrm{His}^{+}$transformants and geneticin resistant transformants was done on minimal dextrose medium (MD, Invitrogen BV) and YPD-G418 medium (Invitrogen BV), respectively. The positive transformants were confirmed by PCR.

\section{Expression of lipases in P. pastoris}

Fermentation experiments were performed in a 7-L bioreactor (New Brunswick, BioFlo 110, USA) as described by $\mathrm{Wu}$ [29]. Briefly, in the glycerol batch phase, $200 \mathrm{~mL}$ of inoculum was directly added into $2.6 \mathrm{~L}$ of a Fermentation Basal Salts Medium and the fermentation conditions were maintained at $28^{\circ} \mathrm{C}, \mathrm{pH} 5.0$ and dissolved oxygen (DO) between 20 and $60 \%$ saturation. Until all of the glycerol was consumed, then the process was converted to a glycerol fed-batch phase, with feeding of $50 \%(v / v)$ glycerol containing $1.2 \%(v / v)$ trace solution at the average rate of $12.4 \mathrm{~g} / \mathrm{L} / \mathrm{h}$. After the desired biomasses were reached, the methanol fed-batch phase was initiated, during which the culture was supplied with $100 \%(v / v)$ methanol containing 1.2\% $(v / v)$ trace solution, and the methanol concentration was 
controlled at $1 \mathrm{~g} / \mathrm{L}$ by an on-line methanol analyzer (FC2002, Shanghai Super-xinxi, China).

\section{Lipase activity determination}

Lipase activity was measured on emulsified $p$ NPP according to Kordel et al. [44]. One enzyme unit was defined as the amount of enzyme releasing $1 \mu \mathrm{mol}$ of $p$-nitrophenol per minute under the assay conditions. And the lipase activity was measured by $\mathrm{pH}$-stat assay using olive oil emulsion as substrate [18]. One unit was defined as the amount of enzyme required to release $1 \mathrm{mmol}$ of fatty acid per minute under assay conditions. All the assays were done in triplicate, and significant differences $(\mathrm{p}<0.05)$ were measured.

\section{Lipase purification}

The recombinant enzymes from the culture supernatant after cultivation for $76 \mathrm{~h}$ were purified through ultrafiltration, SP-Sepharose column, Phenyl-sepharose 6 FF column as described by $\mathrm{Yu}[28]$.

\section{Effect of temperature and $\mathrm{pH}$ on enzyme stability and activity}

Optimal pH was determined by examining the activity of the enzyme at $40^{\circ} \mathrm{C}$ in the range of $\mathrm{pH} 5.0 \sim 11.0$. The $\mathrm{pH}$ stability was measured by incubating lipase solution in buffers $(50 \mathrm{mM}, \mathrm{pH} 5.0 \sim 11.0)$ for $1 \mathrm{~h}$ at $25^{\circ} \mathrm{C}$ and analyzing the residual activity. Optimal temperature was determined by measuring the enzyme activity at optimal $\mathrm{pH}$ under various temperatures $\left(20 \sim 60^{\circ} \mathrm{C}\right)$. Thermostability was determined by pre-incubating the purified enzyme in the temperature range of $20 \sim 60^{\circ} \mathrm{C}$ for $0.5 \mathrm{~h}$. Lipase activity was determined by $p \mathrm{NPP}$ assay.

\section{Kinetic parameters}

The interfacial kinetic parameters $k^{*}$ cat and $K^{*}$ were determined in a heterogeneous medium using $p$ NPP as substrate according to the method described by Burdette et al. [45].

\section{Preparation of immobilized lipase}

The crude lipase from supernatant of the culture was lyophilized and redissolved in $50 \mathrm{mM}$ Tris- $\mathrm{HCl}$ buffer ( $\mathrm{pH}$ 8.5). The method for immobilization of the lipase was described by Wang et al. [14]. Briefly, the macroporous anion exchange resin Amberlite IRA-93 $(1 \mathrm{~g})$ and the lipase $(2 \mathrm{mg})$ were mixed together in $50 \mathrm{mM}$ Tris- $\mathrm{HCl}$ buffer $(\mathrm{pH} 8.5)$ at $20^{\circ} \mathrm{C}$ for $4 \mathrm{~h}$ at $160 \mathrm{rpm}$. These particles above were filtered, and then mixed with fresh lipase $(2 \mathrm{mg})$ and glutaraldehyde $(0.5(v / v) \%$ based on total volume) in $5 \mathrm{~mL}$ buffer at $28^{\circ} \mathrm{C}$ for $20 \mathrm{~min}$. The immobilized lipase was rinsed thrice with $15 \mathrm{~mL}$ Tris- $\mathrm{HCl}$ buffer [2]. The activity of the immobilized lipase (U/g support) was $65 \mathrm{U} / \mathrm{g}$.

\section{Enzymatic methanolysis reaction}

The methanolysis reaction carried out with the immobilized lipase or the free lipases in the solventfree system in screw-capped $50-\mathrm{mL}$ vials on a shaker at $160 \mathrm{rpm}$ and $40^{\circ} \mathrm{C}$ for $48 \mathrm{~h}$, unless indicated specifically. The reaction mixture contained $10 \mathrm{~g}$ tung oil, a certain amount of methanol, enzyme and water with a total volume around $13 \mathrm{~mL}$. Details about molar ratio of methanol to oil, enzyme concentration based on oil weight (wt.\%), and the initial water added based on oil weight (wt.\%) were specified for each case. Methanol was added by four steps. The first portion of methanol and $10 \mathrm{~g}$ of oil were added at the start of the reaction; the second, the third and the fourth portion of methanol were added at an interval of $8 \mathrm{~h}$. Reactions were performed in triplicate.

\section{Gas chromatography analysis}

The FAME contents in the reaction mixture were quantified using a gas chromatography (Agilent 7890, USA) equipped with a flame ionization detector (FID). The column was a Nukol capillary column $(0.25 \mathrm{~mm} \times 60 \mathrm{~m}$, Supelco, USA). Helium was used as a carrier gas. The column temperature was kept at $100^{\circ} \mathrm{C}$ for $1 \mathrm{~min}$, heated to $230^{\circ} \mathrm{C}$ at $4^{\circ} \mathrm{C} / \mathrm{min}$, held at that degree for $25 \mathrm{~min}$. The temperatures of the injector and detector were set at $300^{\circ} \mathrm{C}$. Methyl heptadecanoate served as the internal standard for GC. Aliquots of $100 \mu \mathrm{L}$ samples were taken from the reaction mixture and centrifuged at $12000 \mathrm{rpm}$ for $10 \mathrm{~min}$ to obtain the upper layer, and were diluted in n-hexane and mixed with methyl heptadecanoate. Then, analyses were done by injecting $1 \mu \mathrm{l}$ sample into the column. Methyl palmitate (C16:0), methyl stearate (C18:0), methyl oleate (C18:1), methyl linoleate (C18:2), methyl linolenate (C18:3), methyl elaeostearate (C18:3), methyl eicosenoate (C20:1) and methyl behenate (C22:0) were used as standards. FAME yield (\%) was defined as FAME amount produced divided by initial amount of oil $(\mathrm{g} / \mathrm{g})$.

\section{Central composite rotatable design and statistical analysis} RSM was used to evaluate the best conditions for the FAME yield. A five-level-three-factor CCRD, including six replicates at the center point, totaling 20 assays, was adopted to evaluate the effects of enzyme dosage, molar ratio of methanol to oil and water content on the FAME yield of the reaction in this study. The corresponding CCRD was shown in Table 1. The data obtained were fitted to a second-order polynomial equation using the software Design-Expert 8.0.7.1:

$$
Y=\beta_{0}+\sum_{i=1}^{3} \beta_{i} X_{i}+\sum_{i=1}^{3} \beta_{i i} X_{i}^{2}+\sum_{i=1}^{2} \sum_{j=i+1}^{3} \beta_{i j} X_{i} X_{j}
$$

where $Y$ is the response (\% FAME yield), $\beta_{0}, \beta_{i}, \beta_{i i}$ and $\beta_{i j}$ are the regression coefficients for the intercept, linear, 
quadratic and interaction terms, respectively and $X_{\mathrm{i}}$ and $X_{\mathrm{j}}$ are the independent variables. Design-Expert 8.0.7.1 was used for analysis of variance (ANOVA) and predicting the optimal conditions for the enzymatic reaction.

\section{Operational stability of the immobilized r27AROL}

Each batch of the reaction was carried out at the optimized conditions by adding $5.66 \mathrm{wt} \%$ of the initial water based on oil weight, 3.88 of methanol to tung oil molar ratio and 13.24 wt.\% of enzyme concentration based on oil weight at $40^{\circ} \mathrm{C}$ for $48 \mathrm{~h}$. After each batch, the immobilized r27AROL was recovered by filtration, washed two times with cold hexane, then vacuum-dried before use in the subsequent batch.

\begin{abstract}
Abbreviations
ROL: The $R$. oryzae lipase; proROL: The $R$. oryzae prolipase; proAROL: The chimeric $R$. oryzae prolipase; r27AROL: The truncated chimeric $R$. oryzae prolipase secreted by Pichia pastoris; r28ROL: The truncated non-chimeric $R$. oryzae prolipase secreted by Pichia pastoris; mROL: The mature $R$. oryzae lipase; RCL: The $R$. chinensis lipase; FAME: Fatty acid methyl esters; RSM: Response surface methodology; CCRD: Central composite rotatable design; DCW: Dry cell weight; FID: Flame ionization detector; pNPP: pnitrophenyl palmitate.
\end{abstract}

\section{Competing interests}

The authors declare that they have no competing interests.

\section{Authors' contributions}

YXW and XY designed the research and prepared the manuscript. YXW, SC, GYL did the experiments. RX helped to revise the manuscript. All authors read and approved the final manuscript.

\section{Acknowledgments}

Financial support from the National High Technology Research and Development Program of China (863 Program) (No. 2012AA022207 and 2010AA101501), the National Key Basic Research and Development Program of China (973 Program) (No. 2011CB710800), the Fundamental Research Funds for the Central Universities (JUSRP11014), the Programme of Introducing Talents of Discipline to Universities (111 Project) ( 111-2-06 ), and the Ministry of Education, R.P. China, and from NSFC (20802027) are greatly appreciated.

\section{Author details}

'State Key Laboratory of Food Science and Technology, the Key Laboratory of Industrial Biotechnology, Ministry of Education, School of Biotechnology, Jiangnan University, 1800 Lihu Avenue, Wuxi 214122, Jiangsu, China. ${ }^{2}$ Center for Advanced Biotechnology and Medicine, Department of Molecular Biology and Biochemistry, Rutgers University, Piscataway, NJ 08854, USA.

Received: 14 October 2012 Accepted: 14 February 2013

Published: 21 February 2013

\section{References}

1. Narasimharao K, Lee A, Wilson K: Catalysts in production of biodiesel: A review. J Biobased Mater Bio 2007, 1:19-30.

2. Bajaj A, Lohan P, Jha PN, Mehrotra R: Biodiesel production through lipase catalyzed transesterification: an overview. J Mol Catal B: Enzym 2010, 62:9-14.

3. Bankovic-llic IB, Starnenkovic OS, Veljkovic VB: Biodiesel production from non-edible plant oils. Renew Sust Energ Rev 2012, 16:3621-3647.

4. Basumatary S: Non-edible oils of assam as potential feedstocks for biodiesel production: a review. J Chem Biol Phys Sci 2013, 3:551-558.

5. Chen Y-H, Chen J-H, Luo Y-M: Complementary biodiesel combination from tung and medium-chain fatty acid oils. Renew Energ 2012, 44:305-310.
6. Park J-Y, Kim D-K, Wang Z-M, Lu P, Park S-C, Lee J-S: Production and characterization of biodiesel from tung oil. Appl Biochem Biotech 2008, 148:109-117.

7. Chen $\mathrm{Y}-\mathrm{H}$, Chen J-H, Chang C-Y, Chang C-C: Biodiesel production from tung (Vernicia montana) oil and its blending properties in different fatty acid compositions. Bioresource Technol 2010, 101:9521-9526.

8. Fjerbaek L, Christensen KV, Norddahl B: A review of the current state of biodiesel production using enzymatic transesterification. Biotechnol Bioeng 2009, 102:1298-1315.

9. Shang $Q$, Jiang W, Lu H, Liang B: Properties of Tung oil biodiesel and its blends with O(\#) diesel. Bioresource Technol 2010, 101:826-828.

10. Van Do M, Chen Y-H, Chang C-C, Chang M-C, Chang C-Y: Biodiesel production from Tung oil and blended oil via ultrasonic transesterification process. J Taiwan Inst Chem E 2011, 42:640-644.

11. Chen G, Ying M, Li W: Enzymatic conversion of waste cooking oils into alternative fuel-biodiesel. Appl Biochem Biotech 2006, 132:911-921.

12. Li Z, Li X, Wang Y, Wang Y, Wang F, Jiang J: Expression and characterization of recombinant Rhizopus oryzae lipase for enzymatic biodiesel production. Bioresource Technol 2011, 102:9810-9813.

13. Kaieda M, Samukawa T, Matsumoto T, Ban K, Kondo A, Shimada Y, Noda H, Nomoto F, Ohtsuka K, Izumoto E, Fukuda H: Biodiesel fuel production from plant oil catalyzed by Rhizopus oryzae lipase in a water-containing system without an organic solvent. J Biosci Bioeng 1999, 88:627-631.

14. Y-d W, X-y S, Z-I L, Li X, Wang F, Nie X-a, Jiang J-c: Immobilized recombinant Rhizopus oryzae lipase for the production of biodiesel in solvent free system. J Mol Catal B: Enzym 2010, 67:45-51.

15. Di Lorenzo M, Hidalgo A, Haas M, Bornscheuer UT: Heterologous production of functional forms of Rhizopus oryzae lipase in Escherichia coli. Appl Environ Microb 2005, 71:8974-8977.

16. Ueda M, Takahashi S, Washida M, Shiraga S, Tanaka A: Expression of Rhizopus oryzae lipase gene in Saccharomyces cerevisiae. J Mol Catal B: Enzym 2002, 17:113-124.

17. Takahashi S, Ueda M, Atomi H, Beer HD, Bornscheuer UT, Schmid RD, Tanaka A: Extracellular production of active Rhizopus oryzae lipase by Saccharomyces cerevisiae. J Ferment Bioeng 1998, 86:164-168.

18. Minning S, Serrano A, Ferrer P, Sola C, Schmid RD, Valero F: Optimization of the high-level production of Rhizopus oryzae lipase in Pichia pastoris. J Biotechnol 2001, 86:59-70.

19. Resina D, Serrano A, Valero F, Ferrer P: Expression of a Rhizopus oryzae lipase in Pichia pastoris under control of the nitrogen source-regulated formaldehyde dehydrogenase promoter. J Biotechnol 2004, 109:103-113.

20. Minning S, Schmidt-Dannert C, Schmid RD: Functional expression of Rhizopus oryzae lipase in Pichia pastoris: High-level production and some properties. J Biotechnol 1998, 66:147-156.

21. Niu WN, Li ZP, Tan TW: Secretion of pro- and mature Rhizopus arrhizus lipases by Pichia pastoris and properties of the proteins. Mol Biotechnol 2006, 32:73-81.

22. Zhu XL, Ohta $Y$, Jordan F, Inouye M: Pro-sequence of subtilisin can guide the refolding of denatured subtilisin in an intermolecular process. Nature 1989, 339:483-484.

23. Winther JR, Sorensen $P$, Kielland-Brandt MC: Refolding of a carboxypeptidase $Y$ folding intermediate in vitro by low-affinity binding of the proregion. J Biol Chem 1994, 269:22007-22013.

24. Takahashi S, Ueda M, Tanaka A: Function of the prosequence for in vivo folding and secretion of active Rhizopus oryzae lipase in Saccharomyces cerevisiae. Appl Microbiol Biot 2001, 55:454-462.

25. Beer HD, McCarthy JE, Bornscheuer UT, Schmid RD: Cloning, expression, characterization and role of the leader sequence of a lipase from Rhizopus oryzae. Biochim Biophys Acta 1998, 1399:173-180.

26. Beer HD, Wohlfahrt G, Schmid RD, McCarthy JE: The folding and activity of the extracellular lipase of Rhizopus oryzae are modulated by a prosequence. Biochem J 1996, 319(Pt 2):351-359.

27. Schipper MAA: A revision of the genus Rhizopus I. the Rhizopus stolonifergroup and Rhizopus oryzae. Stud Mycol 1984, 25:1-19.

28. Yu XW, Wang LL, Xu Y: Rhizopus chinensis lipase: gene cloning, expression in Pichia pastoris and properties. J Mol Catal B: Enzym 2009, 57:304-311.

29. Wu D, Yu XW, Wang TC, Wang R, Xu Y: High yield Rhizopus chinenisis prolipase production in Pichia pastoris: Impact of methanol concentration. Biotechnol Bioproc E 2011, 16:305-311. 
30. Takahashi S, Ueda M, Tanaka A: Independent production of two molecular forms of a recombinant Rhizopus oryzae lipase by KEX2-engineered strains of Saccharomyces cerevisiae. Appl Microbiol Biot 1999, 52:534-540.

31. Weissman JS, Kim PS: The pro region of BPTI facilitates folding. Cell 1992, 71:841-851.

32. Kohno M, Enatsu M, Takee R, Kugimiya W: Thermal stability of Rhizopus niveus lipase expressed in a kex2 mutant yeast. J Biotechnol 2000, 81:141-150.

33. Skropeta D: The effect of individual N-glycans on enzyme activity. Bioorgan Med Chem 2009, 17:2645-2653.

34. Sheldon RA: Enzyme immobilization: The quest for optimum performance. Adv Synth Catal 2007, 349:1289-1307.

35. Balasubramaniam B, Perumal AS, Jayaraman J, Mani J, Ramanujam P: Comparative analysis for the production of fatty acid alkyl esterase using whole cell biocatalyst and purified enzyme from Rhizopus oryzae on waste cooking oil (sunflower oil). Waste Manage 2012, 32:1539-1547.

36. Li X, He X-Y, Li Z-L, Wang Y-D, Wang C-Y, Shi H, Wang F: Enzymatic production of biodiesel from Pistacia chinensis bge seed oil using immobilized lipase. Fuel 2012, 92:89-93.

37. Brzozowski AM, Derewenda U, Derewenda ZS, Dodson GG, Lawson DM, Turkenburg JP, Bjorkling F, Huge-Jensen B, Patkar SA, Thim L: A model for interfacial activation in lipases from the structure of a fungal lipase-inhibitor complex. Nature 1991, 351:491-494.

38. Noureddini H, Gao X, Philkana RS: Immobilized Pseudomonas cepacia lipase for biodiesel fuel production from soybean oil. Bioresource Technol 2005, 96:769-777.

39. J L, J E: Modern Statistics for Engineering and Quality Improvement. Thomson Learning Academic Resource Center, Pacific Grove, CA.2001 pp.

40. Tamalampudi S, Talukder MR, Hama S, Numata T, Kondo A, Fukuda H: Enzymatic production of biodiesel from Jatropha oil: A comparative study of immobilized-whole cell and commercial lipases as a biocatalyst. Biochem Eng J 2008, 39:185-189.

41. Martinelle M, Holmquist M, Hult K: On the interfacial activation of Candida antarctica lipase $A$ and $B$ as compared with Humicola lanuginosa lipase. Biochim Biophys Acta 1995, 1258:272-276.

42. Ranganathan SV, Narasimhan SL, Muthukumar K: An overview of enzymatic production of biodiesel. Bioresource Technol 2008, 99:3975-3981.

43. Halim SFA, Kamaruddin AH, Fernando WJN: Continuous biosynthesis of biodiesel from waste cooking palm oil in a packed bed reactor: optimization using response surface methodology (RSM) and mass transfer studies. Bioresource Technol 2009, 100:710-716.

44. Kordel M, Hofmann B, Schomburg D, Schmid RD: Extracellular lipase of Pseudomonas sp. strain ATCC21808: purification, characterization, crystallization, and preliminary X-Ray diffraction data. J Bacterio/ 1991, 173:4836-4841.

45. Burdette RA, Quinn DM: Interfacial reaction dynamics and acyl-enzyme mechanism for lipoprotein lipase-catalyzed hydrolysis of lipid p-nitrophenyl esters. J Biol Chem 1986, 261:12016-12021.

doi:10.1186/1754-6834-6-29

Cite this article as: Yu et al:: High-level expression and characterization of a chimeric lipase from Rhizopus oryzae for biodiesel production. Biotechnology for Biofuels 2013 6:29.

\section{Submit your next manuscript to BioMed Central and take full advantage of:}

- Convenient online submission

- Thorough peer review

- No space constraints or color figure charges

- Immediate publication on acceptance

- Inclusion in PubMed, CAS, Scopus and Google Scholar

- Research which is freely available for redistribution

Submit your manuscript at www.biomedcentral.com/submit
Biomed Central 